\title{
Minimal access to male fertility prices online: an analysis of the Society for Assisted Reproductive Technology (SART) clinics
}

\author{
Ryan G. Larsen ${ }^{1}$, Cole S. Bowdino ${ }^{1}$, Melissa A. Mathes ${ }^{2}$, Stephanie L. Gustin ${ }^{2,3}$, Christopher M. Deibert ${ }^{1}$ \\ ${ }^{1}$ Division of Urologic Surgery, University of Nebraska Medical Center, Omaha, NE, USA; ${ }^{2}$ Department of Obstetrics and Gynecology, University of \\ Nebraska Medical Center, Omaha, NE, USA; ${ }^{3}$ Heartland Center for Reproductive Medicine, Omaha, NE, USA \\ Contributions: (I) Conception and design: CM Deibert, RG Larsen, CS Bowdino; (II) Administrative support: CM Deibert, SL Gustin; (III) Provision \\ of study materials or patients: CM Deibert; (IV) Collection and assembly of data: RG Larsen, CS Bowdino, MA Mathes, CM Deibert; (V) Data \\ analysis and interpretation: RG Larsen, CS Bowdino, MA Mathes, CM Deibert; (VI) Manuscript writing: All authors; (VII) Final approval of \\ manuscript: All authors. \\ Correspondence to: Ryan G. Larsen. Medical Student, Urologic Surgery Clinic Lauritzen Outpatient Center, 3rd Floor, 4014 Leavenworth Street, \\ Omaha, NE 68105, USA; University of Nebraska Medical Center, $42^{\text {nd }}$ and Emile St., Omaha, NE 68198, USA. Email: ryan.larsen@unmc.edu.
}

Background: Though insurance coverage is evolving for male infertility services, most patients continue to pay out of pocket. These costs such as semen analysis and intracytoplasmic sperm injection preparation may affect the utilization of those services. We sought to determine online price transparency specifically for male infertility services on the websites of in-vitro fertilization (IVF) clinics in the US.

Methods: In this cross-sectional analysis, pricing data was acquired from each clinic on the Society for Assisted Reproductive Technology (SART) website as of July 2019. Each website was examined for availability and cost of services. Pricing data that required applying for a quote or a phone call was excluded. Mean price was calculated for each service. Additionally, practice location in an insurance coverage mandated state (ICMS) was also analyzed to evaluate for any effect on price transparency.

Results: Only $24.7 \%$ (89/361) of SART clinic websites included any pricing information. Of clinics with websites (361/383), 16.3\% (59/361) had $\geq 2$ prices reported and only 5.0\% (18/361) had $\geq 6$ prices reported. Only 3.6\% (13/361) reported prices for male-related infertility services. Average semen analysis price was $\$ 161$ of 10 reporting clinics. Four clinics reported sperm cryopreservation or annual sperm storage price, $\$ 388$ and $\$ 555$, respectively. Sperm retrieval cost $\$ 244$ at the two reporting clinics. ICMS did not affect male price transparency, ICMS 3.1\% (6/194) vs. non-ICMS 4.2\% (7/167) (P=0.576).

Conclusions: Price transparency of SART clinics on websites is relatively poor with only about onequarter of clinics providing any cost information at all. Male infertility related pricing information is even more rarely reported compared to other IVF services potentially causing a stronger barrier for males to pursue infertility treatment.

Keywords: Male factor; price; in-vitro fertilization (IVF)

Submitted May 23, 2020. Accepted for publication Sep 11, 2020.

doi: 10.21037/tau-20-944

View this article at: http://dx.doi.org/10.21037/tau-20-944

^ ORCID: 0000-0003-0248-0872. 


\section{Introduction}

The United States spends more per capita on health care than any other developed nation (1). Recently, the United States federal government has placed focus on price transparency in health care with the intention to decrease health care spending and allow greater consumer choice. Though insurance coverage is evolving for infertility services, most patients and couples continue to pay out-ofpocket for much, if not all, of their treatment. Prior research has evaluated the out-of-pocket expense infertility couples incur, ranging from $\$ 912$ up to $\$ 19,234$ (2). When selecting a fertility clinic, many patients will review the website first including a search for prices of fertility treatment. The cost of treatment is also one of the first questions asked at initial appointments during discussion of work-up and treatment recommendations. Overall, male-related factors are the sole cause of infertility in couples $20 \%$ of the time while $20-40 \%$ of the time male infertility is a contributing factor (3). The price of male-related infertility services such as semen analysis, semen cryopreservation, and in-vitro fertilization (IVF) with intracytoplasmic sperm injection (ICSI) may affect the utilization of those services by patients due to the financial and social burden of acquiring infertility treatment. There has yet to be defined availability of online pricing for infertility services. We sought to determine online price transparency specifically as it relates to male infertility services on the websites of Society for Assisted Reproductive Technology (SART) member clinics nationwide. We present the following article in accordance with the MDAR reporting checklist (available at http:// dx.doi.org/10.21037/tau-20-944).

\section{Methods}

In this cross-sectional analysis, pricing data was acquired by searching each infertility clinic listed on the SART website as of July 2019. Of the 383 clinics listed on the SART website, 361 clinics had webpages. Thus, 361 total clinics was used for statistical purposes. Each website was individually examined for availability of services and price information by searching through all menus pertaining to financial or general patient information. Services searched included: male-related infertility services (semen analysis, sperm cryopreservation, annual storage of sperm, and sperm retrieval); initial clinic consultation, female services such as monitoring labs, intrauterine insemination (IUI), IVF with and without medications, ICSI, embryo cryopreservation, embryo annual storage fee, frozen embryo transfer, egg cryopreservation cycle, donor egg cycle, embryo biopsy, embryo retrieval and transvaginal ultrasound. Only pricing data that was readily accessible by website search was included. Pricing data that required applying for a "quote" or requiring a phone call was not included as the goal was only to determine online availability. Degree of price transparency was noted by recording the number of price conditions reported by each individual clinic. A mean price was calculated for each service. For clinics that offered a range as a price, an average of the maximum and minimum of that range was calculated. This resulting number was used in mean price calculations. Each website was also examined for financing information, noting thirdparty financing or financing by the clinic (self-financing). Additionally, practice location in an insurance coverage mandated state (ICMS) was also analyzed to evaluate for any effect on price transparency online. This study was exempt for IRB review at the University of Nebraska Medical Center. The authors received no financial support for the research, authorship, and publication of this article. ICMJE guidelines were followed in authoring this article.

\section{Statistical analysis}

A chi-square test was utilized to determine any significant difference in the number of clinics that reported price data in ICMS $v s$. non-ICMS, as well as the number of clinics that reported price data in university $v s$. non-university associated clinics. To determine any differences in prices in ICMS $v s$. non-ICMS clinics for IVF cycle prices, a two-tailed Student's $t$-test assuming unequal variance was used. Only prices for IVF cycles without medications were compared for the purposes of this statistical analysis.

\section{Results}

Only $24.7 \%(89 / 361)$ of SART affiliated IVF clinic websites included any cost or pricing information (Figure 1). Of clinics with websites (361/383), 16.3\% (59/361) had $\geq 2$ prices reported and only $5.0 \%$ (18/361) had $\geq 6$ prices reported (Table 1). Thirteen percent of clinics (7/54) associated with universities reported price data. This was statistically different from the $26.7 \%(82 / 307)$ non-university associated clinics that reported price data $(\mathrm{P}=0.031)$. Sixty-four-point-eight $(234 / 361)$ of SART clinics mentioned financing options, including clinic selffinancing $10.2 \%(37 / 361)$, third party financing $62.6 \%$ 


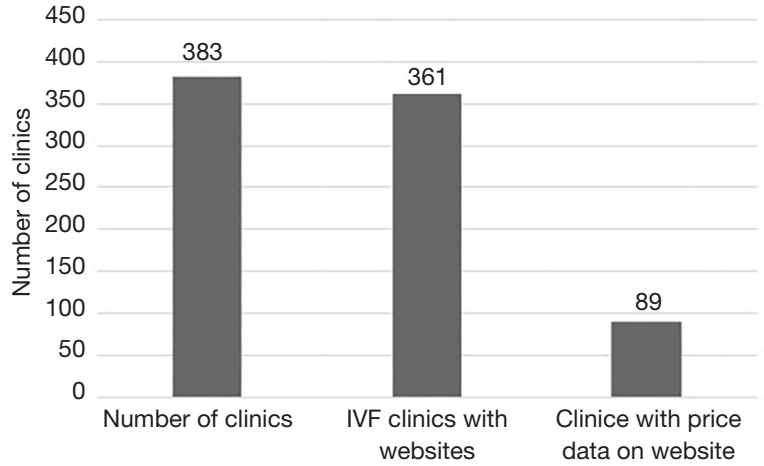

Figure 1 Price transparency of IVF clinics displayed by a histogram showing the number of clinic websites that provided price data pertaining to either male or female infertility services. IVF, in-vitro fertilization.

Table 1 Degree of price transparency for clinics with websites pertaining to all male and female infertility services. Measured as percentage of total clinics reporting a certain number of price conditions

\begin{tabular}{lcc}
\hline $\begin{array}{l}\text { Number of price } \\
\text { conditions reported }\end{array}$ & $\begin{array}{c}\text { Number of clinics } \\
\text { with websites }\end{array}$ & $\begin{array}{c}\text { Percentage of total } \\
\text { clinics with websites }\end{array}$ \\
\hline$\geq 2$ & $59 / 361$ & $16.3 \%$ \\
$\geq 4$ & $37 / 361$ & $10.2 \%$ \\
$\geq 5$ & $25 / 361$ & $6.9 \%$ \\
$\geq 6$ & $18 / 361$ & $5.0 \%$ \\
$\geq 10$ & $7 / 361$ & $1.9 \%$ \\
\hline
\end{tabular}

Table 2 Top six price conditions that were reported across all IVF clinics with websites, in descending order. Both male and female infertility services were assessed. All other price conditions were reported by less than 20 clinics

\begin{tabular}{lc}
\hline Service & Number of clinics \\
\hline IVF cycle without medications & 51 \\
Frozen embryo transfer & 29 \\
Egg cryopreservation cycle & 24 \\
IVF cycle medications & 23 \\
Donor egg cycle & 23 \\
IUI cycle & 21 \\
\hline
\end{tabular}

IVF, in-vitro fertilization; IUI, intrauterine insemination.
(226/361) or both.

Nineteen-point-nine percent (72/361) reported IVFrelated prices (IVF cycle with/without medications and IVF medications alone). Average IVF price (without medications) was $\$ 9,279$. The most reported price was IVF without medications (51/89). Table 2 displays the other most reported prices of services. Average price of IVF with medications was $\$ 12,923$ and average price of IVF medications alone was $\$ 4,398$.

Only $3.6 \%$ of clinics with websites (13/361) reported prices for male-related infertility services. The degree of price transparency for male-related infertility services is reported in Table 3. Of the 10 clinics with pricing information for semen analysis, the average price was $\$ 161$. Four clinics reported pricing information for the price of sperm cryopreservation or the annual price of sperm storage, with an average of $\$ 388$ and $\$ 555$, respectively. Of the two clinics with pricing information for sperm retrieval, the average price was $\$ 244$.

Comparing clinics in and out of ICMS, 13.4\% (26/194) of ICMS clinics reported prices of IVF cycle specific services. The average price of an IVF cycle (without medications) in an ICMS was \$9,359. Fifteen percent (25/167) of non-ICMS clinics reported prices of IVF cycles, with the average price being reported as $\$ 9,195$. The number of clinics that reported in ICMS $v s$. non-ICMS was not significant $(\mathrm{P}=0.670)$. The average prices between ICMS and non-ICMS for IVF cycles (without medication) were not statistically significant $(\mathrm{P}=0.832)$.

Just $3.1 \%(6 / 194)$ of ICMS and $4.2 \%(7 / 167)$ of nonICMS clinics reported any male infertility services price data. There was no significant difference in the number of clinics in and out of ICMS that reported prices $(\mathrm{P}=0.576)$. Table 4 provides a breakdown of what price conditions were reported for ICMS $v s$. non-ICMS, as well as the average prices for each male infertility service.

\section{Discussion}

In this original evaluation, overall price transparency by SART clinics nationwide is poor at $25 \%$, yet many clinics do mention financing options for care. When the degree of price transparency is examined, it shows that even when a clinic reports some price data, it is rarely more than 2 prices with 
Table 3 Degree of price transparency for clinics with websites for male-related infertility services only. Measured as percentage of total clinics that reported a cost for each respective service

\begin{tabular}{lcc}
\hline Service & Number of clinics with websites & Percentage of total clinics with websites \\
\hline Sperm analysis & $10 / 361$ & $2.77 \%$ \\
Semen/sperm cryopreservation & $4 / 361$ & $1.11 \%$ \\
Semen/sperm annual storage fee & $4 / 361$ & $1.11 \%$ \\
Sperm retrieval & $2 / 361$ & $0.55 \%$ \\
\hline
\end{tabular}

Table 4 Comparing the price transparency of male infertility services between insurance coverage mandated states and non-insurance coverage mandated states

\begin{tabular}{|c|c|c|c|c|}
\hline Service & \multicolumn{2}{|l|}{ ICMS } & \multicolumn{2}{|l|}{ Non-ICMS } \\
\hline Semen analysis & 3 & $\$ 160$ & 7 & $\$ 161$ \\
\hline Sperm cryopreservation & 4 & $\$ 388$ & 0 & - \\
\hline Sperm annual storage fee & 2 & $\$ 600$ & 2 & $\$ 509$ \\
\hline
\end{tabular}

ICMS, insurance coverage mandated states.

only $16.3 \%$ of clinics reporting 2 or more prices on their websites. With only $1.9 \%$ of clinics reporting 10 or greater prices, over $98 \%$ of clinics nationwide have room to improve to allow patients to evaluate whether pursuing infertility services is financially feasible for them and their individual budgets. This is especially pertinent in today's world as the millennial and generation $\mathrm{Z}$ populations are coming of an age where they will be seeking infertility treatment as they mature into adulthood. In a study, $54 \%$ of millennials (ages 18 to 24) search online for health information before seeing a doctor (4). These two generations are more likely than previous generations to go online to search for the array and prices of services that may be provided by individual clinics before going through traditional channels such as requesting a quote or visiting with physicians as the initial contact to the infertility clinic (5).

Universities reported well below the national average of price transparency with only $13 \%$ of university-associated fertility clinics reporting any price data vs. $25 \%$ of clinics nationwide. This may further increase the barrier to pursuing infertility services by patients who reside in areas where a university-associated IVF clinic is their only option.

The degree of price transparency for male-specific infertility services is even more poorly reported than general IVF services with only $3.6 \%$ of clinics nationwide reporting male-specific infertility services. Though the price of a semen analysis is a small fraction of IVF prices, this remains an area where clinics can better provide price details to their patients. Providing price transparency for male-related infertility services is important because 20 $40 \%$ of the time male infertility is a contributing factor to a couple's infertility (3). Also, all men have a semen analysis done at least once during their evaluation and treatment (6).

Insurance coverage mandated by states does not appear to affect price transparency of IVF-specific prices. Clinics that report IVF cycle price data (without medications) in non-ICMS and ICMS are nearly equal at $15.0 \%$ and $13.4 \%$, respectively. The average price of IVF cycles without medications in ICMS is slightly higher but is not statistically significant.

Additionally, it does not appear that insurance coverage mandated by states affects the price transparency of malespecific infertility services. Since male-specific services are so poorly reported, the sample size may not be large enough to identify differences between ICMS and non-ICMS for such services at this time. The role of local insurance coverage also matters greatly, even in ICMS. Plans may cover different lifetime or yearly amounts for fertility care and each plan has different requirements in terms of out of pocket and copayments. Listing the price the clinic charges 
for sperm retrieval for example, is only part of the parallel process of defraying expenses through insurance.

The lack of price transparency online has been studied in other areas of medicine. For example, it was found that $18 \%$ of children's hospitals listed prices on their websites for tonsillectomy-adenoidectomy (7). Yet, the lack of price transparency regarding infertility services has not been reported. While the lack of price transparency does not affect the utilization of some medical services as much, it certainly affects the utilization of a service such as infertility treatment that can have substantial out of pocket costs for the patient.

Increasing price transparency has shown to improve patient-centered health care, particularly in cancer treatment. Sharing prices in cancer care has been shown to enhance "shared decision making" between physicians and patients to help make the best choices for each individual patient (8). It may also allow for greater "diagnosis" of financial assistance needs for less obvious patients that may otherwise not have been referred to financial counselors (8). Greater transparency earlier in the process may also allow for patients to budget and plan for the financial burden that comes with added health care services that is associated with a cancer diagnosis and subsequent surveillance (8). These benefits of price transparency likely are present in infertility services and may also add the extra benefit of allowing patients to pursue a diagnosis in the first place by being able to decipher how much the initial tests or treatments may cost them.

Future investigations may include price transparency from simply calling the clinic to receive a quote on the prices of services available by phone but not online.

\section{Limitations}

Three independent evaluators of the SART clinic websites were used to collect data. Not all SART clinics have developed websites available to evaluate the pricing further limiting the price transparency for infertility services. Comparing male-related infertility treatment prices in ICMS $v s$. non-ICMS is limited due to the small sample size in each that recorded prices. Initial workup and treatment, such as semen analysis and IUI, may be offered at other sites not identified within the SART clinic list. These outside clinic websites were not assessed or included in our evaluation.

\section{Conclusions}

Price transparency of SART clinics on-line is relatively uncommon with only about one-quarter of clinics providing any price information at all. When examined further, the degree of price transparency shows that only a few clinics report more than two prices. Price of IVF services is a significant barrier to receiving care as many patients must pay out of pocket for these treatments. With the lack of pricing information available, it may delay or restrict patients from pursuing assisted reproductive technology for fertility preservation and/or infertility diagnoses. Malerelated infertility treatment pricing information is even more rarely reported compared to other IVF services potentially causing a stronger barrier for males to pursue infertility treatment.

\section{Acknowledgments}

Thank you to the Society of Assisted Reproductive Technology for storing the data that allowed this article to come to fruition.

Funding: None.

\section{Footnote}

Reporting Checklist: The authors have completed the MDAR reporting checklist. Available at http://dx.doi.org/10.21037/ tau-20-944

Data Sharing Statement: Available at http://dx.doi. org/10.21037/tau-20-944

Peer Review File: Available at http://dx.doi.org/10.21037/ tau-20-944

Conflicts of Interest: All authors have completed the ICMJE uniform disclosure form (available at http://dx.doi. org/10.21037/tau-20-944). The authors have no conflicts of interest to declare.

Ethical Statement: The authors are accountable for all aspects of the work in ensuring that questions related to the accuracy or integrity of any part of the work are appropriately investigated and resolved. This study was exempt for IRB review at the University of Nebraska Medical Center.

Open Access Statement: This is an Open Access article distributed in accordance with the Creative Commons Attribution-NonCommercial-NoDerivs 4.0 International 
License (CC BY-NC-ND 4.0), which permits the noncommercial replication and distribution of the article with the strict proviso that no changes or edits are made and the original work is properly cited (including links to both the formal publication through the relevant DOI and the license). See: https://creativecommons.org/licenses/by-nc-nd/4.0/.

\section{References}

1. U.S. Health Care Spending Highest Among Developed Countries. 2019, January 7. Retrieved December 8, 2019. Available online: https://www.jhsph.edu/news/newsreleases/2019/us-health-care-spending-highest-amongdeveloped-countries.html

2. Wu AK, Odisho AY, Washington SL 3rd, et al. Out-ofpocket fertility patient expense: data from a multicenter prospective infertility cohort. J Urol 2014;191:427-32.

3. Thonneau P, Marchand S, Tallec A, et al. Incidence and main causes of infertility in a resident population $(1,850,000)$ of three French regions (1988-1989). Hum

Cite this article as: Larsen RG, Bowdino CS, Mathes MA, Gustin SL, Deibert CM. Minimal access to male fertility prices online: an analysis of the Society for Assisted Reproductive Technology (SART) clinics. Transl Androl Urol 2020;9(5):21072112. doi:10.21037/tau-20-944
Reprod 1991;6:811-6.

4. Comstock J. Survey: 54 percent of millennials look online before choosing a doctor. 2015, August 31.

Retrieved December 7, 2019. Available online: https:// www.mobihealthnews.com/46432/survey-54-percent-ofmillennials-look-online-before-choosing-a-doctor

5. Fronstin P. Consumer Engagement in Health Care Among Millennials, Baby Boomers, and Generation X: Findings from the 2017 Consumer Engagement in Health Care Survey. March 5, 2018. EBRI Issue Brief, No. 444. Available online: http://dx.doi.org/10.2139/ssrn.3160059

6. Practice Committee of the American Society for Reproductive Medicine. Diagnostic evaluation of the infertile female: a committee opinion. Fertil Steril 2015;103:e44-e50.

7. Faherty LJ, Wong CA, Feingold J, et al. Pediatric Price Transparency: Still Opaque With Opportunities for Improvement. Hosp Pediatr 2017;7:565-71.

8. Henrikson NB, Shankaran V. Improving Price Transparency in Cancer Care. J Oncol Pract 2016;12:44-7. 